\title{
Prevalence and determinants of tobacco use among Iraqi adolescents: Iraq GYTS 2012
}

\author{
Hamid Y Hussain* and Bushra A Abdul Satar
}

\begin{abstract}
Background: The use of any form of tobacco by 13-15 year old individuals is $10 \%$ globally as identified through the Global Youth Tobacco Survey (GYTS). This study aimed at assessing the prevalence and determinants of tobacco use among Iraqi adolescents.

Methods: A cross sectional study was carried out on 1750 participants selected randomly from preparatory and secondary schools in Baghdad, Iraq in 2012. Through a multistage stratified random sample scheme. The GYTS questionnaire was applied.

Results: The study results indicated that $21.8 \%$ of Iraqi adolescents are tobacco users (male $27.1 \%$, female $12.7 \%$ ). Cigarette smoking was noted as the main type of tobacco use (13.9\%) followed by shisha (4.8\%) and pipe (1.4\%). The stepwise logistic regression indicated a number of predictors of tobacco use. Male adolescents were twice more likely to be tobacco users than female students (OR 2.31; 95\%C.I: 1.57-3.42). Furthermore, students whose parents or sibling were smokers had doubled the risk of tobacco use relative to those with no parents or siblings current smokers (OR1.97; 95\%C.I: 1.04-2.77 and OR1.86; 95\%C.I: 1.21-2.87 respectively). Having close friends who smoked was also identified as an important risk factor towards adolescent tobacco use. Those who reported that some of their friends smoked were 2.67 times more likely to be smokers (95\%C.I: 1.83-3.89), while those who reported that most/all of their friends were smokers were 8.18 times more likely to be smokers themselves (95\%C.I: 4.65-14.39).
\end{abstract}

Conclusion: Smoking rates among Iraqi adolescents were found to be among the higher rates of adolescent smoking prevalence in the Middle East. Multiple family and peer related characteristics were related to tobacco use. Preventive activities should take place to curb the tobacco epidemic in Iraq.

Keywords: Adolescents, Determinants, Smoking, Prevalence, Tobacco use, GYTS

\section{Introduction}

Adolescents are a vulnerable population in terms of health related behaviors due to their unique bio-psych-social characteristics, with tobacco experimentation a prominent behavior with potentially grave consequences, especially among adolescents in developing countries [1,2]. Tobacco use is shifting from the developed world to developing countries, especially low- and middle-income countries, such as those in the Middle East [3,4]. To date, there is limited available information on the prevalence and correlates of tobacco use among Iraqi adolescents [5]. One such study is the Kurdistan-Iraq, Global Youth
Tobacco Survey which noted a prevalence of current cigarette smoking of $15.3 \%$, while indicating the role of parental and peer smoking, male gender, increased pocket money and perceptions that boys or girls who smoked were attractive as factors related to tobacco use [5]. However, there is limited documentation of the prevalence of tobacco use in the rest of Iraq, a country that has suffered deeply from three devastating wars and long term sanctions, factors that may have affected tobacco use among Iraqi youth. With the above in mind the aim of this study was to assess the prevalence and determinants of tobacco use among the adolescent population of Bagdad, Iraq in 2012.

\footnotetext{
* Correspondence: hussainh569@gmail.com

Department of Community Medicine, Faculty of Medicine, University of Baghdad, Baghdad, Iraq
}

\section{() Biomed Central}

(C) 2013 Hussain and Abdul Satar; licensee BioMed Central Ltd. This is an Open Access article distributed under the terms of the Creative Commons Attribution License (http://creativecommons.org/licenses/by/2.0), which permits unrestricted use, distribution, and reproduction in any medium, provided the original work is properly cited. 


\section{Methods}

A school-based analytical cross-sectional study was conducted in both preparatory and secondary schools in, Baghdad/ Iraq from $1^{\text {st }}$ Jan- $1^{\text {st }}$ June, 2012. A multistage stratified random sample technique, with proportional allocation according to the number of schools was used. Stratification was based upon the regions (Two river sides regions), sex (male, female), type of school (governmental vs. private) and age categories.

The list of schools was obtained from the Ministry of Education. The selection of the private and governmental schools were carried out proportionally according to the number of schools; one public school to 4 private schools were selected to a total of 20 schools, 10 males and 10 females within each class were randomly selected from each of grade (preparatory: Years 7-9 and secondary Years:10-12). The total sample size amounted to 1951. The questionnaires of 201 students were incomplete in most items, thus were excluded, leaving a total sample size of 1750 students within the analysis.

Operational definitions for smoking and other variables were based on the World Health Organization GYTS questionnaire that has been applied within other studies [4].

Descriptive statistics were performed for quantitative variables (mean, standard deviation and range). Calculation of $95 \%$ confidence intervals around the proportions of tobacco use was performed. Chi-square test was used for testing the relationship between socio-demographic factors, knowledge, attitude and tobacco use. So as to assess the determinants of tobacco use, a stepwise logistic regression analysis was performed on the following factors: type of school, age, sex, sibling, parents, and close friends smoking, exposure to smoking in public places, attitudes and father education. Odds Ratios (OR) and 95\% Confidence Intervals (95\%C.I) are also presented. Data analysis was performed with the Statistical Package for Social Science (SPSS) software program version 19.0.

\section{Results}

The study revealed that the prevalence of tobacco use among Iraqi $13-18$ year olds is $21.8 \%$ out of which 13.9\% smoke cigarettes, $4.8 \%$ smoke shisha, $1.3 \%$ smoke pipe, $1 \%$ smoke cigars and $0.6 \%$ use smokeless tobacco.

Table 1 presents the frequency distribution of tobacco product used by age of initiation and days of smoking within the last month. When assessing the factors related to smoking among current adolescent cigarette smokers ( $\mathrm{n}=178$ ), we identified that the main source of obtaining tobacco was from friends (51.4\%), schoolmates (19.2\%) and parents (10.4\%). Table 2 depicts the association between tobacco use and selected sociodemographic characteristics. Current smoking status was higher among male adolescents when compared to females, among adolescents within governmental schools and was significantly related to maternal and paternal education. Finally Table 3 presents the results of a stepwise logistic regression of the determinants of tobacco use among Iraqi adolescents. Nine significant predictors were identified and these included the type of school, age, male sex, siblings and parents that smoke, having most of the close friends smoke, being exposed exposure to smoking in public places, personal attitudes and the paternal level of

Table 1 Frequency distribution by age of initiation and days of smoking within the last month among Iraqi adolescents, Baghdad, Iraq 2012S

\begin{tabular}{|c|c|c|c|c|c|c|c|c|c|c|c|c|}
\hline \multirow[b]{3}{*}{ Age of initiation } & \multicolumn{12}{|c|}{ Type of tobacco products } \\
\hline & \multicolumn{2}{|c|}{$\begin{array}{l}\text { Cigarettes } \\
(n=178)\end{array}$} & \multicolumn{2}{|c|}{$\begin{array}{l}\text { Shisha } \\
\text { (n=156 }\end{array}$} & \multicolumn{2}{|c|}{$\begin{array}{l}\text { Pipe } \\
(n=109)\end{array}$} & \multicolumn{2}{|c|}{$\begin{array}{l}\text { Cigar } \\
(n=44)\end{array}$} & \multicolumn{2}{|c|}{$\begin{array}{l}\text { Bidi } \\
(n=19)\end{array}$} & \multicolumn{2}{|c|}{$\begin{array}{l}\text { Smokeless tobacco } \\
(n=26)\end{array}$} \\
\hline & N & $\%$ & $N$ & $\%$ & $\mathrm{~N}$ & $\%$ & $N$ & $\%$ & $N$ & $\%$ & $\mathrm{~N}$ & $\%$ \\
\hline$<10$ & 15 & 6.27 & 12 & 7.7 & 6 & 5.5 & - & - & 2 & 13.3 & 4 & 15.4 \\
\hline $10-11$ & 46 & 19.2 & 47 & 30.1 & 19 & 17.4 & 23 & 52.3 & 6 & 40.0 & 6 & 23.1 \\
\hline $12-13$ & 85 & 35.5 & 27 & 17.3 & 33 & 30.3 & 11 & 25.0 & 1 & 7.6 & 9 & 34.6 \\
\hline $14+$ & 93 & 38.9 & 70 & 44.9 & 51 & 46.8 & 10 & 22.7 & 6 & 40.0 & 7 & 26.9 \\
\hline \multicolumn{13}{|c|}{ Days of tobacco use in the past 30 days } \\
\hline $1-2$ & 91 & 38.0 & 103 & 66.0 & 32 & 29.4 & 22 & 50.0 & 10 & 52.6 & 6 & 23.1 \\
\hline 3-5 & 50 & 20.9 & 10 & 6.4 & 12 & 11.0 & 8 & 18.2 & 4 & 21.1 & 1 & 3.8 \\
\hline $5-9$ & 9 & 3.8 & 12 & 7.7 & 10 & 9.2 & 2 & 4.5 & 2 & 10.5 & 2 & 7.7 \\
\hline $10-19$ & 20 & 8.8 & 7 & 4.5 & 5 & 4.6 & 2 & 4.5 & 2 & 10.5 & 2 & 7.7 \\
\hline $20-29$ & 12 & 5.0 & 14 & 9.0 & 10 & 9.2 & 3 & 6.8 & 0 & 0 & 4 & 15.4 \\
\hline Everyday & 47 & 19.6 & 10 & 6.4 & 40 & 36.7 & 7 & 15.9 & 1 & 5.3 & 11 & 42.3 \\
\hline
\end{tabular}


Table 2 Association between tobacco use and selected sociodemographic characteristics among Iraqi adolescents, Baghdad, Iraq, 2012

\begin{tabular}{lllllll}
\hline $\begin{array}{l}\text { Socio demographic } \\
\text { characteristics }\end{array}$ & \multicolumn{3}{l}{ Tobacco use } & Total N & p-value \\
\cline { 2 - 4 } & yes & yes & no & no & & \\
& $\mathrm{N}$ & $\%$ & $\mathrm{~N}$ & $\%$ & & \\
& & & &
\end{tabular}

School type

$\begin{array}{lllllll}\text { governmental } & 124 & 24.21 & 388 & 75.78 & 512 & <0.001\end{array}$

private

$\begin{array}{lllll}240 & 19.38 & 998 & 79.80 & 1238\end{array}$

Age in Years

$\begin{array}{lllllll}<14 & 65 & 14.06 & 397 & 85.93 & 462 & <0.001 \\ 14-16 & 155 & 26.13 & 438 & 73.68 & 593 & \\ 16+ & 144 & 22.32 & 501 & 77.67 & 645 & \end{array}$

Gender

$\begin{array}{llllllll}\text { male } & 266 & 27.1 & 508 & 72.9 & 981 & <0.001\end{array}$

female

$\begin{array}{lllll}98 & 12.7 & 670 & 87.3 & 768\end{array}$

Grade within the School

$\begin{array}{lllllll}7-9 & 176 & 22.0 & 622 & 78.0 & 798 & <0.001 \\ 10-12 & 188 & 19.7 & 764 & 81.3 & 952 & \end{array}$

Maternal education

illiterate

primary

preparatory

secondary

University/higher

Paternal education

$\begin{array}{lllllll}\text { illiterate } & 98 & 49.0 & 102 & 51.4 & 200 & <0.001 \\ \text { primary } & 93 & 37.2 & 157 & 62.7 & 250 & \\ \text { secondary } & 80 & 29.6 & 190 & 70.4 & 270 & \\ \text { preparatory } & 73 & 19.1 & 308 & 79.9 & 381 & \\ \text { University/higher } & 60 & 9.2 & 589 & 90.8 & 649 & \end{array}$

education. Students aged 16 years or more had higher risk of tobacco use than those aged $<16$ years $(\mathrm{OR}=2.85$, $95 \% \mathrm{CI}=1.78-4.41)$. Male students were more likely to be tobacco users than females (OR 2.31; 95\%C.I.: 1.57-3.42). Furthermore, students whose parents or sibling were smokers had doubled the risk of tobacco use relative to those with no parents or sibling smokers (OR1.97; 95\%C.I: 1.04-2.77 and OR1.86; 95\%C.I: 1.212.87). Having close friends who smoked was also identified as an important risk factor towards adolescent tobacco use. Specifically, those who reported that some of their friends smoked were more than twice more likely to be smokers (OR 2.67 95\%C.I: 1.83-3.89), while those who reported that most/all of their friends were current smokers were 8.18 times more likely to be smokers themselves (95\%C.I: 4.65-14.39).
Table 3 Determinants of tobacco use among adolescents in Baghdad, Iraq 2012

\begin{tabular}{|c|c|c|c|}
\hline Independent variable & OR & (95\% Cl: Lower-Upper) & P-value \\
\hline \multicolumn{4}{|l|}{ Type of school } \\
\hline Private & 1.0 & $(0.8-1.2)$ & $>0.05$ \\
\hline Governmental & 2.08 & $(1.48-2.93)$ & $<0.001$ \\
\hline \multicolumn{4}{|l|}{ Age } \\
\hline 16-18 (vs. 13-16) & 2.88 & $(1.87-4.41)$ & $<0.001$ \\
\hline SEX (male) & 2.31 & $(1.57-3.42)$ & $<0.001$ \\
\hline \multicolumn{4}{|l|}{ PEER-Family smoking } \\
\hline Parents smoking (yes) & 1.97 & $(1.04-2.77)$ & $<0.001$ \\
\hline Siblings smoking (yes) & 1.86 & $(1.21-2.87)$ & 0.005 \\
\hline \multicolumn{4}{|l|}{ CLOSE FRIEND SMOKING } \\
\hline Some of them & 2.67 & $(1.83-3.89)$ & $<0.001$ \\
\hline Most/ all & 8.18 & $(4.65-14.39)$ & $<0.001$ \\
\hline \multicolumn{4}{|c|}{$\begin{array}{l}\text { EXPOSURE TO SMOKING IN } \\
\text { PUBLIC PLACES }\end{array}$} \\
\hline Occasionally & 1.52 & $(1.04-2.24)$ & 0.330 \\
\hline Regularly & 2.75 & $(1.62-4.68)$ & $<0.001$ \\
\hline \multicolumn{4}{|l|}{ ATTITUDE } \\
\hline *Neutral & 2.37 & $(1.37-4.12)$ & 0.002 \\
\hline *Negative & 3.89 & $(2.66-5.37)$ & 0.000 \\
\hline \multicolumn{4}{|l|}{ PATERNAL EDUCATION } \\
\hline Secondary & 0.72 & $(0.48-1.80)$ & 0.114 \\
\hline Primary & 1.78 & $(1.5-2.75)$ & 0.009 \\
\hline Illiterate & 2.02 & $(1.15-4.79)$ & 0.047 \\
\hline
\end{tabular}

Stepwise logistic regression with type of school, age, sex, sibling, parents, close friends smoking, exposure to smoking in public places, attitudes and father education as covariates.

Neutral: The response to the attitude questions of the GYTS was neither no nor yes.

Negative: The mean response to attitude questions was negative (thus pro tobacco).

\section{Discussion}

The current study indicated that prevalence rates of smoking among Iraq adolescents is relatively high, higher than other countries in the Middle East such as Yemen (2003) (7) and Saudi Arabia (2007) where the prevalence of any current tobacco use was $19.3 \%$ \& $17.3 \%$ respectively. Moreover the smoking status of siblings, close friends and family as also the type of school was associated with tobacco use among Iraqi adolescents.

According to data presented from 75 sites in 43 countries and the Gaza Strip/West Bank region by the Global Youth Tobacco Survey (2002) the current use of any tobacco product during adolescence ranged from $3.3 \%$ to $62.8 \%$ with current cigarette smoking ranging from $1 \%$ to $39.6 \%$ [6]. Cigarettes smoking were the predominant form of tobacco use among the current tobacco users (10.7\%). Our noted prevalence is similar to that reported within the last Greek GYTS study (2005) and 
Tehran $[7,8]$ but it was higher than that reported by studies in Oman (2006) [9] where the prevalence of current smoking cigarettes was $4.5 \%$.

As for the results of our multiple logistic regression analysis, we identified that type of schooling and family tobacco use was associated with smoking during adolescence, factors commonly noted as predictors of smoking in other countries [10]. Similarly to our study, the Pokhara study (2003), [9] reported that, boys were 3.15 times more likely to use tobacco compared to girls, and adolescent students from non-governmental schools were 2.58 times more likely to use tobacco than adolescent students from governmental schools. Moreover students were 1.79 times more likely to use tobacco if at least one family member (parents, siblings and other members residing permanently) used tobacco than those who had no family members using tobacco [11].

This study provides significant insight into smoking prevalence and its determinants in Iraqi adolescents, an area relatively untouched to date. However our study has a number of limitations inherent in any cross sectional school survey where data collection is limited to a single time point. Tobacco use was assessed by self-report and therefore, some students may have under reported their tobacco use, especially female students thus the estimated prevalence may be slightly lower than actual prevalence. Moreover, we did not assess other potential influential factors such as exposure to tobacco advertising and promotional activities, which have been noted to be rampant in other low and middle income countries [12].

\section{Conclusions}

Smoking rates among Iraqi adolescents were found to be among the higher rates of adolescent smoking prevalence in the Middle East. Cigarette smoking was the most prevalent type of tobacco use, followed by shisha and pipe smoking. Multiple family and peer related characteristics were related to tobacco use. Preventive activities that could be implemented at either a community or school based level should take place to curb the tobacco epidemic in Iraq [12].

\section{Competing interests}

The authors declared that they have no competing interests.

\section{Authors' contributions}

Both authors read and approved the final manuscript.

Received: 13 December 2012 Accepted: 19 June 2013

Published: 28 June 2013

\section{References}

1. Jha P, Chaloupka FJ: Tobacco Control in Developing Countries. Oxford: Oxford United Press for the World Bank and WHO; 2000. http://tigger.uic.edu/ fjc/ Presentations/Scans/Final\%20PDFs/tc_Itoxvi.pdf.

2. Corrao MA, Guindon GE, Sharma N, Shokoohi DF: Tobacco Country Profiles. American Cancer Society. Atlanta; 2000. http://www.who.int/tobacco/ statistics/country_profiles/en/.
3. The Global Youth Tobacco Survey Collaborative Group (US Centers for Disease Control and Prevention: the World Health Organization, the Canadian Public Health Association, and the U.S. National Cancer Institute). Tobacco use among youth: a cross country comparison. Tob Control 2002, 11:252-270.

4. Siziya S, Muula A, Rudatsikira E: Correlates of current cigarette smoking among in-school adolescents in the Kurdistan region of Iraq. Conflict and Health 2007, 1:13. http:www.conflictandhealth.com/content/1/1/13.

5. The Global Youth Tobacco Survey Collaborative Group: Differences in worldwide tobacco use by gender: Findings from the Global Youth Tobacco Survey. J Sch Health 2003, 73(6):207-215.

6. Kyrlesi A, Soteriades ES, Warren CW: Tobacco use among students aged 13-15 years in Greece: the GYTS Project. BMC Publ Health 2007, 7:3.

7. Heydari GR, Milani HS, Hosseini M, Masjedi MR: Attitude of High School Students of Tehran towards Tobacco Use. Tanaffos 2004, 3(11):29-35.

8. Jaffer YA, Afifi M, Al AF: Knowledge, attitudes and practices of secondaryschool pupils in Oman. Health compromising behaviours. East Med Health Journal 2006, 12(1/2):35-49.

9. Rozi S, Akhtar S, Ali S, Khan J: Prevalence and factors associated with current smoking among high school adolescents in Karachi, Pakistan. Southeast Asian J Trop Med Public Health 2005, 36(2):498-504.

10. Paudel D: Tobacco use among adolescent students in secondary schools of Pokhara. Summary reports. Master's Degree in Public Health (MPH 5th Batch). Maharajgunj Campus: Institute of Medicine Tribhuvan University, Nepal; 2003. http://www.healthnet.org.np/resource/thesis/cmedicine/deepak/tobacco.pdf.

11. Agaku IT, Adisa AO, Akinyamoju AO, Agboola S: A cross-country comparison of the prevalence of exposure to tobacco advertisements among adolescents aged 13-15 years in 20 low and middle income countries. Tob Induc Dis 2013, 11(1):11.

12. Sussman S, Levy D, Lich KH, Cené CW, Kim MM, Rohrbach LA, Chaloupka FJ: Comparing effects of tobacco use prevention modalities: need for complex system models. Tob Induc Dis 2013, 11(1):2.

\section{doi:10.1186/1617-9625-11-14}

Cite this article as: Hussain and Abdul Satar: Prevalence and determinants of tobacco use among Iraqi adolescents: Iraq GYTS 2012. Tobacco Induced Diseases 2013 11:14.

\section{Submit your next manuscript to BioMed Central and take full advantage of:}

- Convenient online submission

- Thorough peer review

- No space constraints or color figure charges

- Immediate publication on acceptance

- Inclusion in PubMed, CAS, Scopus and Google Scholar

- Research which is freely available for redistribution 